\title{
The Lived Experience of Nurses Caring for Patients with COVID-19 in Iran: A Phenomenological Study
}

This article was published in the following Dove Press journal: Risk Management and Healthcare Policy

\section{Zohreh Karimi' \\ Zhila Fereidouni (D) ${ }^{2}$ \\ Mohammad Behnammoghadam 3,4 \\ Nasrollah Alimohammadi ${ }^{5}$ \\ Ali Mousavizadeh ${ }^{6}$ \\ Tahmine Salehi (iD) ${ }^{7}$ \\ Mohammad Saeed Mirzaee ${ }^{8}$ \\ Sobhan Mirzaee (iD ${ }^{9}$ \\ 'Department of Operating Room, School of Paramedicine, Yasuj University of Medical Sciences, Yasuj, Iran; \\ ${ }^{2}$ Department of Medical Surgical Nursing, Nursing School, Fasa University of \\ Medical Sciences, Fasa, Fars, Iran; ${ }^{3}$ School of Nursing, Yasuj University of Medical Sciences, Yasuj, Iran; ${ }^{4}$ School of Nursing and Midwifery, Isfahan University of Medical Sciences, Isfahan, Iran; ${ }^{5}$ Critical Care Nursing Department, Faculty of Nursing and Midwifery, Isfahan University of Medical Sciences, Isfahan, Iran; \\ ${ }^{6}$ Department of Biostatistics and Epidemiology, School of Health, Yasuj University of Medical Sciences, Yasuj, Iran; ${ }^{7}$ Nursing Care Research Center (NCRC), School of Nursing and Midwifery, Iran University of Medical Sciences, Tehran, Iran; ${ }^{8}$ School of Nursing and Midwifery, Iran University of Medical Sciences, Tehran, Iran; ' ${ }^{\text {Student Research }}$ Committee, Yasuj University of Medical Sciences, Yasuj, Iran}

Correspondence: Mohammad Behnammoghadam

School of Nursing and Midwifery, Isfahan University of Medical Sciences, Isfahan, Iran

Email mbehnam1363@gmail.com

Mohammad Saeed Mirzaee School of Nursing and Midwifery, Iran University of Medical Sciences, Tehran, Iran

Email Saeedmirzaee75@gmail.com
Objective: This study aimed to explore the lived experiences of nurses caring for patients with COVID-19 in Iran.

Methods: This study was a descriptive phenomenology. Sampling was purposefully performed, and participants were selected in terms of the inclusion criteria. Data were collected through semi-structured interviews using the WhatsApp mobile messaging application. Colaizzi's method was used to analyse the data. The criteria introduced by Lincoln and Guba were used for the study rigour.

Results: The data were obtained from 12 nurses caring for patients with COVID-19. The mean age of the participants was 29.41 years $(\mathrm{SD}=2.72)$ with a mean work experience of 6.75 years $(\mathrm{SD}=$ 2.52). Three main themes and six subthemes were identified: mental condition (subthemes included "anxiety and stress" and "fear"), emotional condition (subthemes included "suffering and affliction" and "waiting for death"), and care context (subthemes included "turmoil" and "lack of support and equipment").

Conclusion: The results of this study show that nurses working in the wards and care centres designated for patients with COVID-19 are experiencing mental and emotional distress and are working in inadequate professional conditions.

Keywords: nurse experience, nursing care, COVID-19, phenomenology

\section{Introduction}

COVID-19 was first reported in Wuhan, China in 2019. ${ }^{1}$ COVID-19 is caused by the novel severe acute respiratory syndrome (SARS-CoV-2). Coronaviruses are a large family of viruses with four genera: alpha, beta, gamma, and delta. ${ }^{2}$ The most pathological diseases caused by human coronaviruses are SARS, MERS, and COVID-19. ${ }^{3}$ The virus causes disease in humans and animals, following infection with the coronavirus that causes COVID-19, patients can develop respiratory failure, which can lead to death. ${ }^{4}$ Older adults and people with underlying disorders like diabetes are at increased risk for severe illness from COVID-19. The prevalence of COVID-19 has affected societies worldwide. $^{5}$ At present, there are no disease-modifying drugs or vaccines. ${ }^{6}$ To date, $19,462,112$ people have been infected worldwide, of which 722,285 have died from COVID-19. In Iran, according to the latest global report, 324,692 people have been infected and 18,264 have died. ${ }^{7}$

Patients with signs of severe COVID-19-related illness are directed to the hospital for intensive care. ${ }^{8}$ Designated coronavirus units offer special care and facilities for treating 
patients with COVID-19. ${ }^{9}$ These intensive care units are often under strict isolation during epidemics. ${ }^{10}$ Isolation due to hospitalization for COVID-19 can last more than two weeks. Prolonged isolation represents a treat to authentic care for both the patients and healthcare workers. ${ }^{11}$ Currently, nurses are at the forefront of caring for patients with COVID-19. ${ }^{12}$ Nurses need special skills to care for patients experiencing such a health crisis. Briefly, patient care is a complex process. Nurses provide ethical care guided by human interaction to deliver services and impact patient satisfaction. ${ }^{13}$ Limited data regarding the risk for severe disease and the lack of specific drug and intervention therapies have challenged both patient treatment and care; all treatments are symptomatic and performed in terms of experience. ${ }^{14}$ Additionally, patients with COIVD-19 require specialized, supportive care, notably, the expertise, knowledge, attitude, and ability of skilled nurses, as well as the availability of the necessary equipment and infrastructure. ${ }^{15,16}$ Lack of medical facilities and staff, confusion within the treatment system, the unpredictable nature of the disease, social isolation, and the widespread transmission of the virus have had intense consequences for healthcare systems in more than 200 countries globally. Quality nursing care for patients with COVID-19 is a major challenge. ${ }^{17}$ Nurses themselves are exposed to serious risk and even death while administering care for patients with COVID-19. Working stress, the daily influx of patients to hospitals, low hospital capacity, and the substandard ratio of nurses to patients have made the phenomenon of care problematic. Accordingly, it is important to examine the nurses' experience with care. ${ }^{18}$ Care is a highly interactive relationship between patient and nurse that can be explored using various research methods. ${ }^{19}$ Qualitative research can increase understanding of nurses' experiences from life, procedures, processes, and events as they are observed in a natural setting without intervention. The phenomenological approach can provide detailed information regarding human interactions ${ }^{20}$ and lived experiences of nurses caring for patients COVID- $19,{ }^{20}$ and can be used to explore the perceived meaning and challenges of these experiences. $^{21}$ The main guiding philosophy in this study was based on Husserl descriptive phenomenology which focuses on the lived experience of the participants. ${ }^{22}$ No qualitative studies have examined nurses' experience in caring for patients with COVID-19 in this emerging pandemic and healthcare crisis. Therefore, this study was conducted to explore the lived experiences of nurses caring for patients with COVID-19 in Iran.

\section{Methods}

\section{Study Design}

We performed a qualitative descriptive phenomenological study to discover and interpret the meaning of nurses' lived experiences caring for patients with COVID-19. Husserl's four steps of descriptive phenomenology were employed: bracketing, intuiting, analyzing and interpreting. ${ }^{22}$

\section{Sample Strategy and Sampling}

Sampling was purposefully performed, and participants were selected in terms of the inclusion criteria. Sampling was targeted in this study; selected participants were rich in information on the phenomenon. The sample size was not fixed at the onset of the study, and sampling continued to data saturation. The participants included those nurses who cared for the patients with COVID-19 in hospitals at the Coronavirus Center in Iran. These hospitals are the designated treatment and care centres for patients with COVID-19. Additional inclusion criteria were used to select participants: work experience in the designated COVID-19 unit; care of patients with a COVID-19 diagnosis by clinical symptoms, positive testing, or hospitalization; and sufficient availability for the interview session. Exclusion criteria of the study included unwillingness to participate in the study and nurses with a COVID-19 diagnosis. Prior to the interview, informed consent was obtained from the participants.

\section{Data Collection}

Interviews were conducted initially as unstructured with general questions followed by semi-structured interview questions. Sample questions are presented in Table 1. Each interview lasted between 35-70 minutes and was conducted over two sessions if necessary. Due to restrictions in the COVID-19 unit at this time, such as complete isolation, prohibited entry and exit of miscellaneous people in the section, high risk of viral transmission to other individuals, and heavy workload of nurses, the interviews were performed by WhatsApp mobile software (video calling, voice, and text messages). The type of interview was based on the preference of the participants. The interviewers had prior qualitative research and interview experience. The interviews were recorded with the permission of participants by Researchers which were then re-examined and compared with two other experts. 


\section{Data Analysis}

The descriptive Colaizzi method was used to analyse the obtained data. This method consists of seven steps as follows: (1) collecting the participants' descriptions, (2) understanding the depth of the meanings, (3) extracting the important sentences, (4) conceptualizing important themes, (5) categorizing the concepts and topics, (6) constructing comprehensive descriptions of the issues examined, and (7) validating the data following the four criteria set out by Lincoln and Guba (Table 2). ${ }^{23}$

\section{Rigour}

The rigor of this study was based on Lincoln and Guba four criteria: credibility, confirmability, dependability and transferability. ${ }^{24}$ Researchers' established credibility, prolonged engagement with the data, the findings, identification of dissimilar findings and member check. To obtain a thick and rich data set for confirmability, 12 nurse with valuable experience in caring for patients with COVID-19 were recruited. Also the researchers investigated and described all details of the research, from sampling to data collection and analysis, and then compared the data. Two qualitative research specialists ensured the descriptions and coding were accurate. To confirm the obtained results, the researchers used more than two questions to study the phenomenon. Coding systems were used during the analysis process to improve dependability.

\section{Ethical Considerations}

The present study was approved under the ethical code number IR.YUMS.REC.1399.002 from Yasuj University of Medical Sciences in 2020. All the participants completed the written informed consent, all of whom were assured that all their information would be kept confidential, and only the results of the survey would be published anonymously.

\section{Results}

Twelve nurses participated in this study. The mean age of the participants was 29.41 years $(\mathrm{SD}=2.72) .66 .66 \%$ of the participants were women. Overall, most nurses provided ongoing care. Moreover, $58.33 \%$ of the participants worked the morning shift, $25 \%$ worked the evening shift, and $16.66 \%$ worked the night shift. The participants had a mean work experience of 6.75 years $(\mathrm{SD}=2.52)$. Of the total participants, $50 \%$ had one month of work experience in the COVID-19 isolation unit, and the remaining 50\% had two months of work experience in this unit (Table 3). Analysis of the nurses' experiences caring for patients with COVID-19 by descriptive phenomenology revealed three main themes: mental condition, emotional condition, and care context (Table 4).

\section{Mental Condition}

The high mental demands experienced by nurses in COVID-19 centres can jeopardize the quality of care they can provide for their patients. According to nurses, experiences of anxiety and stress, as well as fear, significantly impact the care of patients with COVID-19.

\section{Anxiety and Stress}

Anxiety and stress can have negative effects on patient care as well as the mental health of nurses. These experiences described by nurses indicate that their mental condition is integral to their care for patients and that nurses fully understand the consequences of these conditions on care during the current coronavirus crisis. Nurses stated various causes for their anxiety including an anxious environment, doubts, consequences of the situation, and stress for the occurrence of an unfortunate situation. It is clear that stress and anxiety are important factors that nurses are faced with during this current coronavirus pandemic:

How anxious I am, there is no moment that I am not anxious, my whole body is shaking ... (P10)

Stress becomes a normal issue, when I get close to the patient my whole body sweats, so I cannot work properly. (P2)

Why should the world be so involved and then do nothing? (P3)

\section{Fear}

Fear is usually distinguishable from anxiety. In the COVID19 patient care context, fear leads to a more severe degree of worrying among nurses, specifically as it pertains to becoming infected and transmitting the disease to others:

Maybe I am sick too, if I am a carrier, I might cause others to be infected, my symptom show that I am sick too, I am always afraid I will become sick too, I will easily get the disease, I cannot be here anymore, I wish it would end sooner, I am afraid I will do something wrong for the patients. (P2)

Table I A Sample of the Questions Used in Interviews

\section{Questions:}

I. First of all, tell us about your experience in caring for patients with COVID-19. What experience do you have?

2. Tell us about your daily experiences in caring for patients with COVID-19. 
Maybe I die, but I still have lots of dreams. (P6)

\section{Emotional Condition}

The nurses discussed the experience of long shifts and quarantine conditions in the hospital, namely, the lack of visits and the distance from family. Nurses described being emotionally affected by the suffering and affliction of patients with serious health conditions caused by COVID-19 and by the sense of waiting to die. The emotional involvement in care for these severely affected patients has had a serious impact on care according to the nurses.

\section{Suffering and Affliction}

The nurses described their concerns for the suffering and hardships of the patients facing the severe health consequences of COVID-19. The participants reiterated the experience of feeling constrained by isolation and quarantine practices, as it affected their family processes and even their job performance. Participants noted that the difficulties and emotional involvement with patients in the COVID-19 centres have challenged their practice of principles of genuine nursing care:

I just want to end these difficult days, no one can live with these hardships, people are in trouble, I wish God would help end this tragedy sooner, do you think that I can think about the principles of care now? Do not say that at all, we cannot really see our family, we cannot meet, and it is unbearable. (P7)

I cannot meet my family, we are all in the ward, it is very difficult to be away from my family, everything weighs on me, it is very hard, now think that I will come and think about my care theory, no one can think about these things in this tragedy. (P12)
I am sad for the patients, some of them are very young, I am saddened by their death, a man dies for simple shortness of breath, and they have dreams, what will happen to their poor families. (P3)

\section{Waiting for Death}

The large number of daily deaths following COVID-19 has had negative emotional and professional consequences for nurses. In addition to all the hardships and difficulties caused by heightened pressure in COVID-19 care centres, the fear of dying has become a challenge distracting nurses from genuine patient care; nurses have experienced being consumed by imagining the loss of life or the expectation of death causing them to distance themselves from care.

Several participants voiced concerns about impending death, which extended to patients, self, relatives, and colleagues, which has significantly detracted their focus on care:

Everyone is dying, who cares, this is too much work, the death rate is increasing, I wish no one would be sad, many of our colleagues died, it is hard to believe this number of deaths, the cemeteries have no place anymore. (P5)

Sometimes I think I cannot get too close to the patient, I do not want to die, and the end of this disease is death. (P11)

\section{Care Context}

Turmoil and lack of support and equipment were evident in the nurses' statements concerning the care context. The care context includes various factors, including supportive equipment, personal protection equipment, and facilities, as well as appropriate policies and environmental conditions to provide proper care for the patients with COVID-19. Nurses consider

Table 2 The Stages of Data Analysis Using the Colaizzi Descriptive Method

\begin{tabular}{|c|c|}
\hline Description (Action) & Stage \\
\hline Video calls, voice calls, and messages using WhatsApp and recording the interviews & Collecting descriptions \\
\hline $\begin{array}{l}\text { Transcribing and re-reading the content to gain a general and in-depth understanding of the } \\
\text { participants' statements }\end{array}$ & Understanding the depth of meanings \\
\hline Reviewing the nurses' explanations and specifying the important sentences & Extracting the important sentences \\
\hline $\begin{array}{l}\text { Extracting the important explanations and giving them meaning with specific concepts (expressing } \\
\text { the meaning of the important parts) }\end{array}$ & Conceptualizing the important themes \\
\hline The obtained concepts were placed in specific categories (based on the similarity of concepts). & Categorizing the concepts and topics \\
\hline Clear and unambiguous expression of the description of the phenomenon under study. & $\begin{array}{l}\text { Constructing comprehensive descriptions of } \\
\text { the topics reviewed }\end{array}$ \\
\hline Lincoln and Guba criteria used (credibility, transferability, reliability, and verification) & Validating the findings \\
\hline
\end{tabular}


Table 3 Characteristics of the Nurse Participants

\begin{tabular}{|l|l|l|l|l|l|l|}
\hline ID & Age & Sex & Position & Shift Work & Work Experience & Time to Attend Coronavirus \\
\hline PI & 25 & F & Nurse & Morning & 4 Years & Two Months \\
P2 & 27 & M & Nurse & Morning & 6 Years & One Month \\
P3 & 26 & F & Nurse & Morning & 3 Years & Two Months \\
P4 & 28 & F & Nurse & Morning & 7 Years & One Month \\
P5 & 31 & M & Nurse & Morning & 8 Years & Two Months \\
P6 & 30 & F & Staff & Evening & 8 Years & Two Months \\
P7 & 32 & M & Supervisor & Evening & 10 Years & Two Months \\
P8 & 30 & F & Nurse & Morning & 7 Years & One Month \\
P9 & 31 & F & Nurse & Night & 5 Years & One Month \\
PI0 & 35 & M & Supervisor & Night & 12 Years & Two Months \\
PII & 29 & F & Nurse & Morning & 6 Years & One Month \\
PI2 & 29 & F & Nurse & Evening & 5 Years & Onth \\
\hline M \pm SD & $29.41 \pm 2.74$ & - & - & $6.75 \pm 2.52$ & - \\
\hline Total & N=12 & \multicolumn{5}{l}{} \\
\hline
\end{tabular}

Note: $\mathrm{P}$ indicates participant.

the contextual shortcomings of the health care centre a significant deterrent to providing quality care.

\section{Turmoil}

Nurses described the uncertain treatment and care policies in place for patients with COVID-19 within the designated care centres. Participants emphasized disruption in care, and staffing shortages and restrictions on the COVID-19 unit that affected nursing care:

We cannot cover a large number of the patients, the number of nurses is small, every patient needs as much work as a few ordinary patients, and I do not know how to take care of them anymore. (P4)

I can principally take care when our numbers are so small, so much pressure is on co-workers, you know how many patients come per day, just hospitalization and hospitalization again. (P7)

If there was a clear policy about this condition that we acted based on it, it would be much better, our care is performed based on our previous experiences, I think a series of clear and scientific care and treatment policies should be provided. (P11)

\section{Lack of Support and Equipment}

Nurses indicated that basic medical facilities are insufficient for the care of patients with COVID-19. Participants emphasized the necessity for advanced preparation for critical and emergent healthcare crises, highlighting the importance of specific policies, adequately trained personnel, and the procurement of the necessary equipment for patient care as their primary concerns in the care context.

We do not have enough facilities, there are few basic facilities, this ward is not similar to an isolated ward. (P9)

The cooperation of others is not very good. (P4)

\section{Discussion}

Qualitative research on the patient care experience in the era of COVID-19 is scarce. This study has explored the lived experiences of nurses caring for patients with COVID-19 in designated treatment centres in Iran. Mental condition, emotional condition, and care context were the main themes that emerged from the nurses' statements. Anxiety, stress, fear, witnessing the death of patients and colleagues, substandard care conditions, and a lack of facilities were the most pressing concerns identified in the nurses' statements. The first central theme identified in our study, mental condition, was characterized by feelings of anxiety, stress and fear experienced by the nurses. COVID-19 has caused many problems for health systems. ${ }^{25}$ Currently, nurses are at the forefront of patient care and facility management in COVID-19 centres. Unusually high workplace hardships as a result of these central themes must be countered with self-care to allow nurses to continue to provide high-quality, genuine patient care. ${ }^{26}$ Lack of proper self-care can have serious consequences for patients. ${ }^{27}$ The concerns and anxieties of the nurses involved in this study were often directly linked to the care context surrounding COVID-19. The second theme 
Table 4 Themes and Subthemes Emerging During the Data Analysis

\begin{tabular}{|c|c|c|c|}
\hline Themes & Subthemes & Cods & Participants' comments \\
\hline \multirow[t]{2}{*}{$\begin{array}{l}\text { Mental } \\
\text { condition }\end{array}$} & Stress and anxiety & $\begin{array}{l}\text { Disease contagion } \\
\text { Get in trouble and get } \\
\text { involved } \\
\text { Confusion } \\
\text { Restlessness }\end{array}$ & $\begin{array}{l}\text { "I'm not calm at all, and I do not know what's going on." (P2) } \\
\text { "I don't think anything good will happen." (P4) } \\
\text { "Why should the world be so involved and then do nothing?" (P3) }\end{array}$ \\
\hline & Fear & $\begin{array}{l}\text { Anxiety } \\
\text { To be ready } \\
\text { Terrible situation }\end{array}$ & $\begin{array}{l}\text { "Maybe I die, but I still have lots of dreams." (P6) } \\
\text { "I'm scared for my family and also for myself." (PI) } \\
\text { "How horrible these days are, we're all dying." (P7) }\end{array}$ \\
\hline \multirow[t]{2}{*}{$\begin{array}{l}\text { Emotional } \\
\text { condition }\end{array}$} & Suffering and affliction & $\begin{array}{l}\text { Trouble } \\
\text { A lot of trouble } \\
\text { Limited life }\end{array}$ & $\begin{array}{l}\text { "I don't know what my kids are doing now." (P8) } \\
\text { "These days, all of our work is hard, and people have their own } \\
\text { problems." (P5, PII) } \\
\text { "We just think our lives will get better, but everything is messed up." } \\
\text { (PI0) }\end{array}$ \\
\hline & Waiting for death & $\begin{array}{l}\text { Death of others } \\
\text { Family separation }\end{array}$ & $\begin{array}{l}\text { "Many people will die; disaster is happening." (PI2) } \\
\text { "I haven't met my family for a long time." (P9) }\end{array}$ \\
\hline \multirow[t]{2}{*}{ Care context } & Turmoil & $\begin{array}{l}\text { Work pressure } \\
\text { Inexperience } \\
\text { Chaos } \\
\text { Staff shortage }\end{array}$ & $\begin{array}{l}\text { "We work hard, we work so much." (P2) } \\
\text { "They told me to come and work here, I didn't have much experience." } \\
\text { (P7) } \\
\text { "I don't know how to take care of them, whatever I do, it's just like I do } \\
\text { nothing." (P6) } \\
\text { "The number of nurses is low and the tasks are very high." (PI0) }\end{array}$ \\
\hline & $\begin{array}{l}\text { Lack of support and } \\
\text { equipment }\end{array}$ & $\begin{array}{l}\text { Weakness of support } \\
\text { Inadequate environment } \\
\text { Non-participation }\end{array}$ & $\begin{array}{l}\text { "No one is accountable." (P8) } \\
\text { "We don't have a well-known employment situation, but we have to } \\
\text { work." (P3) } \\
\text { "The cooperation of others is not good at all." (P4) }\end{array}$ \\
\hline
\end{tabular}

of nurses' statements, emotional condition, follows unpleasant events. All of these central themes have interfered with the care focus and professional performance of nurses in Iran. Nursing has always sought to provide effective services and care. $^{28}$ The nurses' statements in this study show that the main theme, care context, has been ineffective at providing appropriate services and care for patients with COVID-19. Moreover, existing stress, complicated patient care, ambiguous disease status, and system inefficiencies can affect the quality of nurses' care. ${ }^{29}$ Deteriorating care quality threatens patient safety. ${ }^{30}$ Patient care is the most important objective of a nurse. ${ }^{31}$ The results of this study show that care under these conditions is difficult and jeopardized. ${ }^{32}$ Nurses should take extreme efforts to remain focused on genuine patient care. ${ }^{33}$ Continuity of nursing care is beneficial to the health and welfare of patients. ${ }^{34}$ The strength of this study was that no similar research has been conducted on these issues so far. A major limitation of this study was that the researchers denied entry to the hospital due to the critical condition of the COVID-19 units; an alternative approach for conducting interviews using the mobile messaging platform WhatsApp partially overcame this limitation.

\section{Conclusion}

The results of this study show that nurses working in the wards and care centres designated for patients with COVID-19 are experiencing inappropriate mental, emotional, and professional conditions; despite these obstacles, nurses continue to provide proper care for their patients. The experiences of fear and the unfavourable situation of the nurses have created a contradiction. Nurses need more support in the setting of COVID-19 care because nursing care practices are at serious risk. According to the nurses, policymakers and nursing managers must consider the necessity for nursing care in the current coronavirus crisis, must develop an advance plan, and must provide necessary training for nurses for adapting to the sudden and extreme demands of caring for patients in COVID-19 centres. These results also recommend that detailed and practical research on nursing care be performed to strengthen to approach to nursing care in the COVID-19 context. 
Accordingly, quantitative and qualitative research in the field of care for patients with coronavirus can prepare the field of nursing for a novel emergent epidemic.

\section{Acknowledgment}

We thank all the nurses who helped us conduct this research. The authors appreciate Professor Fariba Taleghani for the assistance with this research and Dr Hossein Mari Oryad, Deputy of the Research Center of Yasuj University of Medical Sciences, for financial and spiritual support.

\section{Disclosure}

The authors report no conflicts of interest in this work.

\section{References}

1. Lin Q, Zhao S, Gao D, et al. A conceptual model for the coronavirus disease 2019 (COVID-19) outbreak in Wuhan, China with individual reaction and governmental action. Int J Infect Dis. 2020;93:211-216.

2. Lai CC, Shih TP, Ko WC, Tang HJ, Hsueh PR. Severe acute respiratory syndrome coronavirus 2 (SARS-CoV-2) and coronavirus disease-2019 (COVID-19): the epidemic and the challenges. Int $J$ Antimicrob Agents. 2020;55(3):105924. doi:10.1016/j. ijantimicag.2020.105924

3. Li G, De Clercq E. Therapeutic options for the 2019 novel coronavirus (2019-nCoV). Nat Rev Drug Discov. 2020;19(3):149-150. doi:10.1038/d41573-020-00016-0

4. Zhu N, Zhang D, Wang W, et al. A Novel Coronavirus from Patients with Pneumonia in China, 2019. N Engl J Med. 2020;382(8):727-733.

5. Shrivastava SR, Shrivastava PS. Minimizing the risk of international spread of Coronavirus Disease 2019 (COVID-19) outbreak by targeting travelers. $J$ Acute Dis. 2020;9(2):47-48.

6. Bogoch II, Watts A, Thomas-Bachli A, Huber C, Kraemer MU, Khan K. Potential for global spread of a novel coronavirus from China. $J$ Travel Med. 2020;27(2):taaa011. doi:10.1093/jtm/taaa011

7. World Health Organization. Coronavirus disease (COVID-19) Situation Report - 202. Geneva: WHO; 2020. Available from: https://www.who.int/docs/default-source/coronaviruse/situationreports/20200809-covid-19-sitrep-202.pdf?sfvrsn=2c7459f6_2. Accessed August 9, 2020.

8. Qarawi ATA, Ng SJ, Gad A, et al. Awareness and Preparedness of Hospital Staff against Novel Coronavirus (COVID-2019): A Global Survey-Study Protocol. SSRN. 2020. doi:10.2139/ssrn.3550294

9. Bearman G, Pryor R, Albert H, et al. Novel coronavirus and hospital infection prevention: preparing for the impromptu speech. Infect Control Hosp Epidemiol. 2020;1-7.

10. Park HC, Lee S-H, Kim J, et al. Effect of isolation practice on the transmission of middle east respiratory syndrome coronavirus among hemodialysis patients: a 2-year prospective cohort study. Medicine. 2020;99(3):e18782. doi:10.1097/MD.0000000000018782

11. McClendon P. Authentic caring: rediscover the essence of nursing. Nurs Manage. 2017;48(10):36-41. doi:10.1097/01.NUMA.0000524813.18664.7c

12. Eghbali M, Negarandeh R, Froutan R. COVID-19 epidemic: Hospital-level response. Nursing Practice Today. 2020;7(2):81-83.

13. Schoenhofer SO, van Wynsberghe A, Boykin A. Engaging robots as nursing partners in caring: nursing as caring meets care-centered value-sensitive design. Int $J$ Hum Caring. 2019;23(2):157-167. doi:10.20467/1091-5710.23.2.157
14. Guo Y-R, Cao Q-D, Hong Z-S, et al. The origin, transmission and clinical therapies on coronavirus disease 2019 (COVID-19) outbreak-an update on the status. Mil Med Res. 2020;7(1):1-10. doi:10.1186/s40779-020-00240-0

15. Huh S. How to train health personnel to protect themselves from SARS-CoV-2 (novel coronavirus) infection when caring for a patient or suspected case. J Educ Eval Health Prof. 2020;17:10. doi:10.3352/ jeehp.2020.17.10

16. Huang C, Wang Y, Li X, et al. Clinical features of patients infected with 2019 novel coronavirus in Wuhan, China. Lancet. 2020;395 (10223):497-506. doi:10.1016/S0140-6736(20)30183-5

17. Qiu H, Tong Z, Ma P, et al. Intensive Care During the Coronavirus Epidemic. Springer; 2020.

18. Schwartz J, King -C-C, Yen M-Y. Protecting health care workers during the COVID-19 coronavirus outbreak-lessons from Taiwan's SARS response. Clin Infect Dis. 2020.

19. Holopainen G, Nyström L, Kasén A. The caring encounter in nursing. Nurs Ethics. 2019;26(1):7-16. doi:10.1177/ 0969733016687161

20. Husserl E. The Phenomenology of Internal Time-Consciousness. Indiana University Press; 2019.

21. Steinbock AJ. The society of phenomenology and existential philosophy. In: The Reception of Husserlian Phenomenology in North America. Springer; 2019:267-281.

22. Polit DF, Beck CT. Nursing Research: Generating and Assessing Evidence for Nursing Practice. 10th ed. Philadelphia, PA: Wolters Kluwer Health; 2017.

23. Colaizzi PF. Psychological research as the phenomenologist views it. In: Valle RS, King M, editors. Existential-phenomenological alternatives for psychology. New York: Oxford University Press; 1978:48-71.

24. Lincoln YS, Guba EG. Naturalistic Inquiry. Newbury Park, CA: Sage; 1985.

25. Bai Y, Yao L, Wei T, et al. Presumed asymptomatic carrier transmission of COVID-19. JAMA. 2020;323(14):1406. doi:10.1001/ jama.2020.2565

26. Xie J, Tong Z, Guan X, Du B, Qiu H, Slutsky AS. Critical care crisis and some recommendations during the COVID-19 epidemic in China. Intensive Care Med. 2020;46(5):837-840.

27. Ross A, Bevans M, Brooks AT, Gibbons S, Wallen GR. Nurses and health-promoting behaviors: knowledge may not translate into self-care. AORN J. 2017;105(3):267-275. doi:10.1016/j. aorn.2016.12.018

28. Lake ET, Germack HD, Viscardi MK. Missed nursing care is linked to patient satisfaction: a cross-sectional study of US hospitals. $B M J$ Qual Saf. 2016;25(7):535-543. doi:10.1136/bmjqs-2015-003961

29. Hamers J, Nijhuis-van der Sanden M, Ettema R, et al. Essential nursing care: most provided, least evidence based. The basic care revisited program. J Adv Nurs. 2016;72(S1):51.

30. Eglseer D, Hödl M, Lohrmann C. Six nursing care problems in hospitals: a cross-sectional study of quality of care. J Nurs Care Qual. 2019;34(1):E8-E14. doi:10.1097/NCQ.0000000000000307

31. Hessels AJ, Wurmser T. Relationship among safety culture, nursing care, and standard precautions adherence. Am J Infect Control. 2020;48(3):340-341. doi:10.1016/j.ajic.2019.11.008

32. Haddad LM, Geiger RA. Nursing Ethical Considerations. 2019.

33. Stewart K, Doody O, Bailey M, Moran S. Improving the quality of nursing documentation in a palliative care setting: a quality improvement initiative. Int $J$ Palliat Nurs. 2017;23(12):577-585. doi:10.12968/ijpn.2017.23.12.577

34. Saunders K, Hagist C, McGuire A, Schlereth C. Nursing Without Caring? A Discrete Choice Experiment About Job Characteristics of German Surgical Technologist Trainees. WHU-Otto Beisheim School of Management; 2019. 


\section{Publish your work in this journal}

Risk Management and Healthcare Policy is an international, peerreviewed, open access journal focusing on all aspects of public health, policy, and preventative measures to promote good health and improve morbidity and mortality in the population. The journal welcomes submitted papers covering original research, basic science, clinical \& epidemiological studies, reviews and evaluations, guidelines, expert opinion and commentary, case reports and extended reports. The manuscript management system is completely online and includes a very quick and fair peer-review system, which is all easy to use. Visit http://www.dovepress.com/testimonials.php to read real quotes from published authors. 